\title{
Adverse Events following AstraZeneca COVID-19 Vaccine in Saudi Arabia: A Cross-Sectional Study among Healthcare and Nonhealthcare Workers
}

\author{
Ahlam A. Alghamdi, b Afrah Alkazemic Abdulrahman Alissab Isra Alghamdid \\ Ghada Alwarafi $^{a}$ Hadeel A. Waggas ${ }^{\mathrm{e}}$ \\ ${ }^{a}$ College of Pharmacy, Princess Nourah bint Abdulrahman University, Riyadh, Saudi Arabia; ${ }^{\text {bPharmaceutical Care }}$ \\ Department, King Abdullah Bin AbdulAziz University Hospital, Riyadh, Saudi Arabia; 'Massachusetts College of \\ Pharmacy and Health Sciences University, Boston, MA, USA; ${ }^{d}$ College of Medicine, Imam Mohammed Ibn Saud \\ Islamic University, Riyadh, Saudi Arabia; 'Department of Medicine, King Abdullah Bin AbdulAziz University Hospital, \\ Riyadh, Saudi Arabia
}

\section{Keywords}

Coronavirus disease $\cdot$ Safety · AstraZeneca COVID-19 vaccine

\begin{abstract}
Introduction: Many COVID-19 vaccines have been emerging with different efficacy and safety profiles. So far, very little attention has been paid to severity and reactogenicity of $\mathrm{CO}$ VID-19 vaccine among healthcare workers. Thus, the aim of this study is to investigate the side effects associated with the first dose of AstraZeneca COVID-19 vaccine among healthcare workers (HCWs) and nonhealthcare workers (non-HCWs). Method: This is an observational cross-sectional study conducted at King Abdullah bin AbdulAziz University Hospital, Saudi Arabia, between February 28 and March 12,2021 . The major outcomes were the reported side effects of day 1 , day 2 , and day 3 after vaccination among HCWs and non-HCWs. Other outcomes included the onset and the duration of the reactions or the side effects that were reported. Results: A total of 526 participants completed the survey with 173 (32.8\%) HCWs and the remaining majority were non-HCWs. Some of the most frequently reported side effects among the participants on the first day were muscle aches (49\%), followed by fever (42\%) and headache (40\%).
\end{abstract}

HCWs experienced more muscle aches, headache, sore throat, and abdominal pain, which were statically significant, compared to non-HCWs. The mean onset of symptoms was $16( \pm 15.3) \mathrm{h}$ in the HCW arm compared with $12.2( \pm 10.2) \mathrm{h}$ in non-HCWs $(p=0.0024)$. Furthermore, the mean duration of symptoms in the HCW group was $37( \pm 19)$ h compared with $32.3( \pm 13) \mathrm{h}$ in the non-HCW group ( $p=0.067)$. Conclusion: The reported side effects were common but not pressing in both groups. HCW respondents appeared to have more $\mathrm{CO}$ VID-19 vaccine-associated symptoms.

(c) 2021 The Author(s)

Published by S. Karger AG, Basel

\section{Introduction}

The coronavirus disease (COVID-19) pandemic, which started in 2019 in China, continues to spread, despite multiple lockdowns and prolonged control measures implemented in most countries [1]. Health care workers (HCWs) are at risk for COVID-19 infection, and reports have described cases in HCWs since early in the outbreak [2]. Besides the high mortality risk, several studies found that COVID-19 has a negative impact on the psychological and well-being of HCWs [3, 4].
(C) 2021 The Author(s)

Published by S. Karger AG, Basel

This is an Open Access article licensed under the Creative Commons Attribution-NonCommercial-4.0 International License (CC BY-NC) (http://www.karger.com/Services/OpenAccessLicense), applicable to the online version of the article only. Usage and distribution for commercial purposes requires written permission.
Correspondence to:

Ahlam A. Alghamdi, ahaalghamdi@pnu.edu.sa 
Table 1. Baseline characteristics of survey participants

\begin{tabular}{llll}
\hline Individual characteristics & $\begin{array}{l}\mathrm{HCW} \\
(n=173)\end{array}$ & $\begin{array}{l}\text { Non-HCW } \\
(n=353)\end{array}$ & $p$ value \\
\hline Age, mean (SD), years & $37(9)$ & $41(14)$ & 0.84 \\
BMI, mean (SD) & $27(8)$ & $27(6.9)$ & 1 \\
Male gender, $n(\%)$ & $83(46.82)$ & $161(51.2)$ & 0.60 \\
Previous COVID-19 infection, $n(\%)$ & $14(8)$ & $22(6.2)$ & 0.46 \\
Healthy, $n(\%)$ & $135(78.03)$ & $295(83.56)$ & 0.60 \\
Comorbidities, $n(\%)$ & & & \\
$\quad$ Lung disease & $15(8.67)$ & $15(4.24)$ & 0.04 \\
$\quad$ Hypertension & $13(7.51)$ & $32(9.06)$ & 0.62 \\
$\quad$ Diabetes mellitus & $8(4.62)$ & $29(8.21)$ & 0.14 \\
$\quad$ Heart disease & $2(1.15)$ & $11(3.11)$ & 0.23 \\
Immune disease & $2(1.15)$ & $2(0.56)$ & 0.60 \\
\hline
\end{tabular}

BMI, body mass index; HCW, healthcare worker.
Since the beginning of the COVID-19 pandemic, major efforts have been executed to develop an effective and safe vaccine [5]. In December 2020, several vaccine candidates were shown to be safe and efficacious in trials, and mass vaccination (in combination with existing control measures) is seen as one of the central elements to controlling the pandemic $[1,6,7]$.

Vaccines mainly act by simulating a natural infection and thereby promoting development of a humoral and cellular immune response aimed at defending the host against a specific pathogen [8]. The majority of the known aftereffects were mild in terms of severity such as headache, pain at the injection site, muscle pain, and fever [9, 10]. There are some serious adverse events reported in COVID-19 vaccine trials, and several European countries withdrew the AstraZeneca vaccine over its alleged link to blood clots [11].

A recent cross-sectional study that was conducted among HCWs in Saudi Arabia showed that 12\% of HCWs were not willing to receive COVID-19 vaccine. Among those, almost half were hesitant to receive the vaccine due to concern about adverse events [12]. Up to our knowledge, there is no study investigating the adverse events among HCWs and non-HCWs in Saudi Arabia. In this study, we report the adverse events following the first dose of AstraZeneca vaccine among HCWs and nonHCWs.

\section{Materials and Methods}

A cross-sectional study was directed at King Abdullah Bin AbdulAziz University Hospital (KAAUH) in Riyadh, Saudi Arabia. A survey was distributed to all individuals who received AstraZeneca vaccine between February 28 and March 12, 2021, at day 3 after vaccine. Two pharmacy interns approached all individuals who received the COVID-19 vaccine by hospital phone on day 3 after vaccination. A description to the study and its objective was provided to all individuals. We included all individuals who got the vaccine in the study period.

\section{Structured Survey}

The structured survey consists of 2 parts. The first part of the survey included information about the demographic data of the participant such as age, weight, height, gender, ethnicity, and comorbid conditions. The second part of the survey included information about the specific symptoms that were experienced by each participant after getting the COVID-19 vaccine. Ten symptoms were listed in the survey including fever, sore throat, muscle pain, eye muscle pain, new loss of smell or taste, shortness of breath, headache, numbness, palpitation, and abdominal pain. Participants were inquired about the side effects they experienced during days 1,2, and 3 after the vaccinations. Also, the participant may add any other symptoms that were not listed in the abovementioned options. In addition to that, the participants were required to describe the severity of each symptom in the first 3 days after getting the vaccine. The scale of severity ranged from no symptoms to severe symptoms. Participants were also asked about the average time their symptoms started and the duration the symptoms persisted. Additionally, participants were asked whether using a pain killer resolved the symptoms that can be managed by the pain killers. Once the participant completed the survey, the data were uploaded and saved into a secure Excel spreadsheet.

\section{Statistical Analysis}

Categorical data were presented as frequencies and percentages and compared using the $\chi^{2}$ test or Fisher's exact test as appropriate. Continuous data were presented as mean with standard deviation or median with interquartile range and compared using the $t$ test for normally distributed data or Mann-Whitney U test for nonnormally distributed data. The data were analyzed using IBM SPSS Statistics (Version 26) predictive analytics software. Significance was assumed for a $p$ value $<0.05$. 
Table 2. Side effects to COVID-19 vaccine reported within 3 days following the first dose

\begin{tabular}{|c|c|c|c|}
\hline Side effect, $n(\%)$ & $\mathrm{HCW}(n=173)$ & Non-HCW $(n=353)$ & $p$ value \\
\hline \multicolumn{4}{|l|}{ Day 1 after vaccination } \\
\hline Muscle pain & $111(64)$ & $151(43)$ & 0.000 \\
\hline Headache & $86(49.7)$ & $124(35)$ & 0.002 \\
\hline Fever & $69(40)$ & $152(43)$ & 0.511 \\
\hline Numbness & $20(12)$ & $25(7)$ & 0.097 \\
\hline Eye muscle pain & $18(10)$ & $15(4)$ & 0.012 \\
\hline Gastrointestinal symptoms & $16(9)$ & $6(2)$ & 0.000 \\
\hline Sore throat & $14(8)$ & $8(2.3)$ & 0.004 \\
\hline Palpitation & $12(7)$ & $13(4)$ & 0.126 \\
\hline Smell/taste loss & $4(3.2)$ & $3(0.8)$ & 0.225 \\
\hline Shortness of breath & $6(3.5)$ & $17(4.8)$ & 0.651 \\
\hline \multicolumn{4}{|l|}{ Day 2 after vaccination } \\
\hline Muscle pain & $96(56)$ & $119(34)$ & 0.000 \\
\hline Headache & $64(37)$ & $90(26)$ & 0.008 \\
\hline Fever & $59(34)$ & $105(30)$ & 0.318 \\
\hline Numbness & $15(9)$ & $12(3)$ & 0.019 \\
\hline Eye muscle pain & $16(9)$ & $16(5)$ & 0.029 \\
\hline Gastrointestinal symptoms & $12(7)$ & $9(3)$ & 0.030 \\
\hline Sore throat & $14(8)$ & $4(1)$ & 0.000 \\
\hline Palpitation & $11(6)$ & $9(3)$ & 0.049 \\
\hline Smell/taste loss & $6(4)$ & $1(0.3)$ & 0.006 \\
\hline Shortness of breath & $3(2)$ & $12(3)$ & 0.405 \\
\hline \multicolumn{4}{|l|}{ Day 3 after vaccination } \\
\hline Muscle pain & $44(25)$ & $52(15)$ & 0.004 \\
\hline Headache & $29(17)$ & $44(13)$ & 0.182 \\
\hline Fever & $12(7)$ & $37(11)$ & 0.205 \\
\hline Numbness & $7(4)$ & $6(2)$ & 0.134 \\
\hline Eye muscle pain & $5(3)$ & $7(2)$ & 0.541 \\
\hline Gastrointestinal symptoms & $8(5)$ & $8(2)$ & 0.176 \\
\hline Sore throat & $11(6)$ & $0(0)$ & 0.000 \\
\hline Palpitation & $6(4)$ & $8(2)$ & 0.404 \\
\hline Smell/taste loss & $2(1)$ & $0(0)$ & 0.108 \\
\hline Shortness of breath & $4(2)$ & $7(2)$ & 0.757 \\
\hline
\end{tabular}

$\mathrm{HCW}$, healthcare worker.

\section{Results}

The study included 528 participants who were willing to participate in the study. Thirty-three percent (173/528) of them were HCWs while the remaining were nonHCWs. The mean age of HCWs was 37 years compared to 41 years in non-HCWs. Approximately $80 \%$ of participants were healthy in both groups, and the distribution of comorbidities was balanced except for lung disease which was more predominant among HCWs. Fourteen $(8 \%)$ in HCWs and $22(6.2 \%)$ in non-HCWs had a previous COVID-19 infection. The baseline characteristics of the participants are presented in Table 1.

The most reported side effects by participants on the first day were muscle aches (49\%), followed by fever
(42\%) and headache (40\%). HCWs experienced more muscle aches, headache, sore throat, and abdominal pain which were statistically significant compared to nonHCWs. Participant responses about the side effects they experienced during days 1,2 , and 3 after the vaccinations are presented in Table 2. Additionally, a summary on the occurrence and severity of adverse events reported by HCWs and non-HCWs is shown in Figure 1.

Approximately $78 \%$ of HCWs used analgesics to alleviate the adverse events compared to $71.9 \%$ of nonHCWs. Among those who used analgesics, $85 \%$ of HCWs reported a symptom relief compared to $91 \%$ of nonHCWs. The mean onset of symptoms was $16 \mathrm{~h}$ in the HCW group compared with $12.2 \mathrm{~h}$ in the non-HCW group ( $p=0.0024)$. Furthermore, the mean duration of 


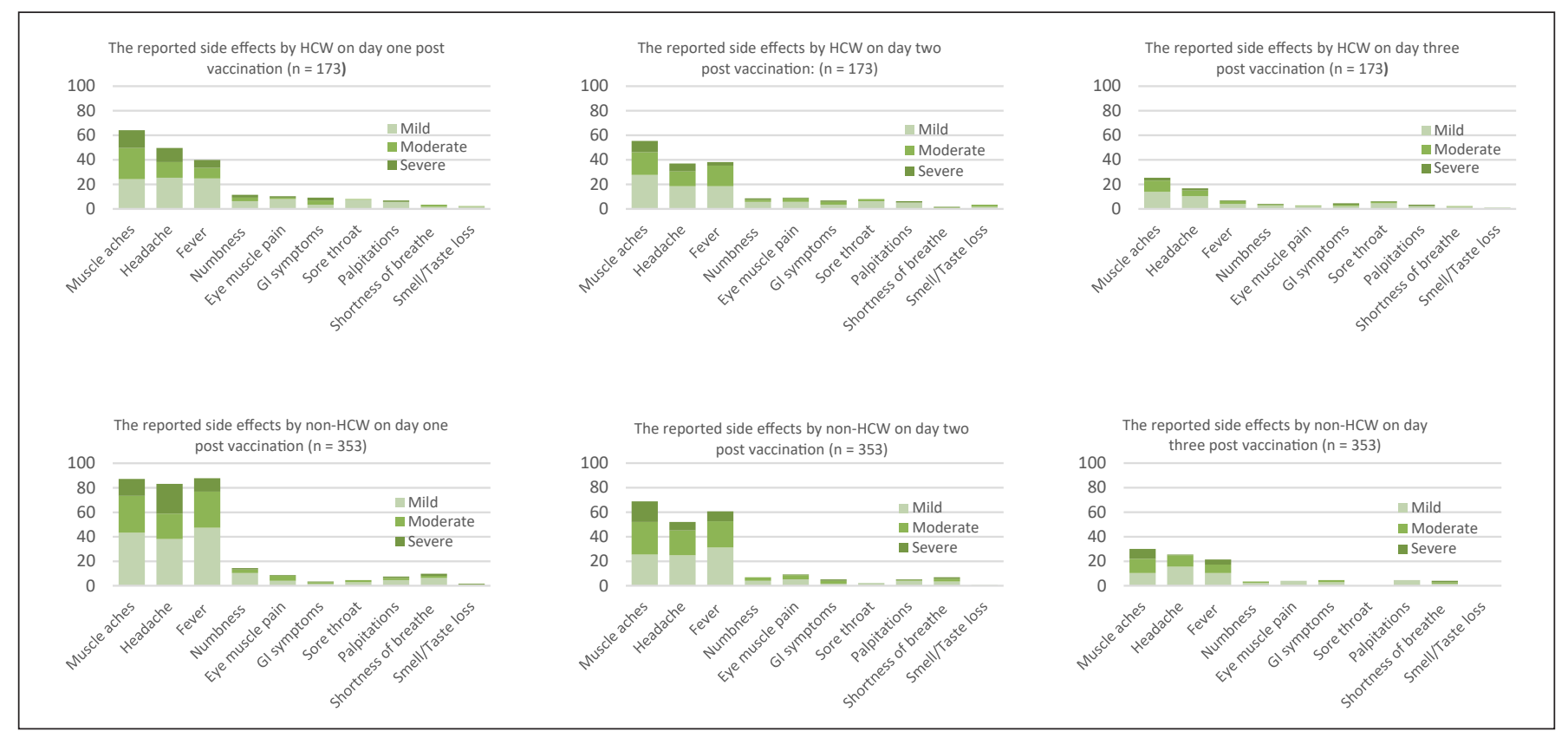

Fig. 1. The differences in reported side effects between HCWs and non-HCWs during the first 3-day period after vaccine. HCWs, healthcare workers.

Table 3. Onset and duration of the side effects and whether symptoms were resolved by pain killers

\begin{tabular}{llll}
\hline & $\begin{array}{l}\text { HCW } \\
(n=173)\end{array}$ & $\begin{array}{l}\text { Non-HCW } \\
(n=353)\end{array}$ & $p$ value \\
\hline $\begin{array}{l}\text { Onset of side effect, mean } \pm \text { SD, h } \\
\text { Duration of side effect, mean } \pm \text { SD, h }\end{array}$ & $16(15.38)$ & $12.2(10.2)$ & 0.002 \\
$\begin{array}{l}\text { Symptoms relieve on painkillers, } n(\%) \\
\quad \text { No }\end{array}$ & $37(19.5)$ & $32.32(13.6)$ & 0.067 \\
$\quad$ Yes & $115(6.46)$ & $7(1.98)$ & 0.371 \\
$\quad$ Not taken & $38(21.96)$ & $233(66)$ & 1 \\
$\quad$ Maybe & $14(8.09)$ & $12(3.39)$ & 0.405 \\
\end{tabular}

HCW, healthcare worker.

symptoms in the HCW group was $37 \mathrm{~h}$ compared with $32.3 \mathrm{~h}$ in the non-HCW group ( $p=0.067)$. Results on the duration of symptoms and need for analgesics for symptom relief are illustrated in Table 3.

\section{Discussion/Conclusion}

The present study was designed to determine if there is a difference in the adverse events following AstraZeneca COVID-19 vaccine among HCWs and non-HCWs. The vast majority of individuals were healthy in both groups, and the distribution of comorbidities was bal- anced except for lung disease, which was more predominant among HCWs.

In our study, there have been no reports of severe complications linked to the AstraZeneca vaccine in a single center in Saudi Arabia for both groups. The adverse events and severity was more predominant in the HCW group compared to the non-HCW group following the first dose of AstraZeneca vaccine. The most reported adverse events on the first day were muscle pain (49\%), followed by fever $(42 \%)$ and headache $(40 \%)$. HCWs experienced more muscle pain, headache, sore throat, and gastrointestinal symptoms, which were statistically significant, compared to non-HCWs. On the second and 
third day, the reported side effects as well as the severity of the side effects decreased among all participates. This result is consistent with other COVID-19 vaccines in which the highest percentage of adverse events were noticed in the first day and then decreased markedly through the seventh day [13].

In March, a study reported findings in $5 \mathrm{HCW}$ who were 32-54 years of age and presented with thrombosis 7-10 days after receiving the first dose of AstraZeneca vaccine [14]. Therefore, the use of AstraZeneca vaccine was withheld temporarily in some European countries due to the serious thromboembolic events $[11,15]$. A recent study assessed the clinical and laboratory features of 11 patients in whom thrombosis had developed after receiving AstraZeneca vaccine. Of those, 9 were women, with a median age of 36 years, beginning 5-16 days after vaccination [16]. The problem with spontaneous reports of suspected thromboembolic events to AstraZeneca vaccine is difficult to distinguish a causal effect from a coincidence because the COVID-19 infection is associated with blood clotting as well $[15,16]$. The serious adverse event started with simple symptoms like headache and fatigue and continued beyond 3 days. Therefore, AstraZeneca vaccine can result in the rare development of thrombotic events, and this highlights the importance of educating the recipients about reporting any persistent symptoms after vaccination and the healthcare workers pay more attention to childbearing women.

This study did not show any significant difference between HCWs and non-HCWs regarding the duration of adverse events. Both groups behaved similarly, and all the adverse events subsided with time as shown in Figure 1. This observed finding may be explained by the high utilization of analgesics in both groups. This finding further supports the benefits of prophylaxis paracetamol which was used in phase $1 / 2$ of AstraZeneca vaccine and showed a significant reduction in adverse events including pain, muscle ache, and headache [17].

The difference in side effects between HCW and nonHCW groups might be due to the psychosocial factor. As reported in a cross-sectional study in Saudi Arabia, 37\% of HCWs were not sure to uptake the COVID-19 vaccine and preferred to wait, and $11 \%$ said "no" to uptake the vaccine [12]. HCWs may be more sensitive to symptoms due to their medical education (e.g., knowledge or higher education) than non-HCWs. Another suggested factor is the possibility of previous asymptomatic infection among HCWs which leads to a stronger immune response.

The current study has some limitations. First, it was conducted in a single center with convenience sampling which may limit the generalizability of the findings. Participants were liable for recall bias when responding to the survey on the third day after receiving the vaccine, thus influencing accurate retrieving of events. Using the subjective scale to determine the severity of symptoms, for example, mild, moderate, or severe, rather than using an objective criterion may have created variation in participants' responses.

\section{Statement of Ethics}

The study was conducted according to the guidelines of the Declaration of Helsinki and approved by the KAAUH Institutional Review Board (IRB Log \#: H-01-R-059). All subjects have given written informed consent.

\section{Conflict of Interest Statement}

The authors declare no conflicts of interest.

\section{Funding Sources}

This research was funded by the Deanship of Scientific Research at Princess Nourah bint Abdulrahman University through the Fast-track Research Funding Program. The funder had no role in the design of the study; in the collection, analyses, or interpretation of data; in the writing of the manuscript; or in the decision to publish the results.

\section{Author Contributions}

Ahlam Alghamdi and Afrah Alkazemi contributed to conceptualization; Isra Alghamdi and Ghada Alwarafi contributed to data curation; Abdulrahman Alissa contributed to project administration; Abdulrahman Alissa and Afrah Alkazemi contributed to writing - original draft; Ahlam Alghamdi and Hadeel Alwagas contributed to writing - review and editing. All authors have read and agreed to the published version of the manuscript.

\section{Data Availability Statement}

The data relating to this study are available from the corresponding author upon reasonable request. 


\section{References}

1 Abu Jabal K, Ben-Amram H, Beiruti K, Batheesh Y, Sussan C, Zarka S, et al. Impact of age, ethnicity, sex and prior infection status on immunogenicity following a single dose of the BNT162b2 mRNA COVID-19 vaccine: real-world evidence from healthcare workers, Israel, December 2020-January 2021. Euro Surveill. 2021;26(6):2100096.

2 Chou R, Dana T, Buckley DI, Selph S, Fu R, Totten AM. Update alert 4: epidemiology of and risk factors for coronavirus infection in health care workers. Ann Intern Med. 2020 May 5;173:143-4.

3 Al Sulais E, Mosli M, AlAmeel T. The psychological impact of COVID-19 pandemic on physicians in Saudi Arabia: a cross-sectional study. Saudi J Gastroenterol. 2020;26(5):249_ 55.

4 Florin M, Pinar U, Chavigny E, Bouaboula M, Jarboui L, Coulibaly A, et al. Socio-economic and psychological impact of the COVID-19 outbreak on private practice and public hospital radiologists. Eur J Radiol. 2020;132: 109285.

5 Shrotri M, Swinnen T, Kampmann B, Parker EPK. An interactive website tracking COVID-19 vaccine development. Lancet Glob Health. 2021;9(5):e590-2.
6 Wiersinga WJ, Rhodes A, Cheng AC, Peacock SJ, Prescott HC. Pathophysiology, transmission, diagnosis, and treatment of coronavirus disease 2019 (COVID-19): a review. JAMA. 2020;324(8):782-93.

7 Piroth L, Cottenet J, Mariet AS, Bonniaud P, Blot M, Tubert-Bitter P, et al. Comparison of the characteristics, morbidity, and mortality of COVID-19 and seasonal influenza: a nationwide, population-based retrospective cohort study. Lancet Respir Med. 2021;9(3): 251-9.

8 Salvagno GL, Henry BM, di Piazza G, Pighi L, De Nitto S, Bragantini D, et al. Anti-SARSCoV-2 receptor-binding domain total antibodies response in seropositive and seronegative healthcare workers undergoing $\mathrm{CO}$ VID-19 mRNA BNT162b2 vaccination. Diagnostics 2021;11(5):832.

9 Polack FP, Thomas SJ, Kitchin N, Absalon J, Gurtman A, Lockhart S, et al. Safety and efficacy of the BNT162b2 mRNA Covid-19 vaccine. N Engl J Med. 2020;383(27):2603-15.

10 Baden LR, El Sahly HM, Essink B, Kotloff K, Frey S, Novak R, et al. Efficacy and safety of the mRNA-1273 SARS-CoV-2 vaccine. N Engl J Med. 2021;384(5):403-16.

11 Østergaard, Dinesen S, Horváth-Puhó E, Thomsen RW, Sørensen HT. Thromboembolism and the Oxford-AstraZeneca COVID-19 vaccine: side-effect or coincidence? The Lancet. 2021;397(10283):1441-3.
12 Barry M, Temsah MH, Alhuzaimi A, Alamro $\mathrm{N}, \mathrm{Al}$-Eyadhy A, Aljamaan F, et al. COVID-19 vaccine confidence and hesitancy among healthcare workers: a cross-sectional survey from a MERS-CoV experienced nation. medRxiv. 2020

13 Chapin-Bardales J, Gee J, Myers T. Reactogenicity following receipt of mRNA-based COVID-19 vaccines. JAMA. 2021;325(21):22012.

14 Schultz NH, Sørvoll IH, Michelsen AE, Munthe LA, Lund-Johansen F, Ahlen MT, et al. Thrombosis and thrombocytopenia after ChAdOx1 nCoV-19 vaccination. N Engl J Med. 2021;384(22):2124-30.

15 Wise J. COVID-19: European countries suspend use of Oxford-AstraZeneca vaccine after reports of blood clots. BMJ. 2021;372:n699.

16 Greinacher A, Thiele T, Warkentin TE, Weisser K, Kyrle PA, Eichinger S. Thrombotic thrombocytopenia after ChAdOx1 nCov19 vaccination. N Engl J Med. 2021;384(22): 2092-101.

17 Folegatti PM, Ewer KJ, Aley PK, Angus B, Becker S, Belij-Rammerstorfer S, et al. Safety and immunogenicity of the ChAdOx $1 \mathrm{nCoV}$ 19 vaccine against SARS-CoV-2: a preliminary report of a phase $1 / 2$, single-blind, randomised controlled trial. Lancet. 2020; 396(10249):467-78. 